\title{
Reply to "Comments on 'The Financial Dilemma of Students Pursuing an Atmospheric Science Graduate Degree in the United States'"
}

\author{
Dylan R. Card, Heather S. Sussman, and Ajay Raghavendra
}

AFFILIATIONS: Card and Sussman-Department of Atmospheric and Environmental Sciences, University at Albany, State University of New York, Albany, New York; Raghavendra-U.S. Army, Fort Eustis, Virginia

DOI:10.1175/BAMS-D-20-0320.1

CORRESPONDING AUTHOR: Heather S. Sussman, hsussman@albany.edu

In final form 15 February 2021

C2021 American Meteorological Society

For information regarding reuse of this content and general copyright information, consult the AMS

Copyright Policy.
S tuecker et al. (2021) have provided comments on the use of meal and incidental (M\&IE) rates over regional price parities (RPP) in Card et al. (2020). The authors of Card et al. (2020) would like to thank Stuecker et al. (2021) for their evaluation of the research methods and suggestions for future work on this topic. Stuecker et al. (2021) argue that the use of M\&IE may have disproportionately impacted the University of Hawai'i at Mānoa (UHM) and the University of Alaska Fairbanks (UAF). In this reply, the authors of Card et al. (2020) will address why M\&IE was chosen over RPP and demonstrate that M\&IE and RPP track similarly.

Reply to the use of M\&IE in Card et al. (2020)

Stuecker et al. (2021) argued that Card et al. (2020) should have used RPP over M\&IE for analyzing how costs vary between different states. One of the goals of Card et al. (2020) was for university administrators to consider ways to lessen the potential financial burden many graduate students endure. University administrators are likely familiar with M\&IE compared to other government statistics, such as RPP, since M\&IE rates are often considered for any business-related travel. However, the Department of Defense (DoD) sets the M\&IE rates for Hawaii and Alaska, rather than the General Services Administration (GSA), which is the agency responsible for setting the rates for the contiguous United States (CONUS). This could have resulted in disparities between the M\&IE values for outside CONUS (OCONUS). Furthermore, RPP is expressed as a percentage of the overall national price level. However, the goal of Card et al. (2020) was to only compare cost of living disparities between the assessed institutions. This goal cannot be achieved using RPP because RPP is calculated using a national mean cost, which considers all areas in the United States equally, and distracts from the focused goal of Card et al. (2020). M\&IE allows for the comparison at the institutional level, not relative to a national mean, making it a superior metric for localized areas. Since M\&IE is calculated by the DoD for Hawaii and Alas- 
$\mathrm{ka}$, and not the GSA, calculations using M\&IE were removed for both schools in the revised version of Card et al. (2020). As a consequence, an effective income was not reported for UHM and UAF in Card et al. (2020). While this exclusion alters the effective income standardization for the other schools, it does not impact the overall results.

\section{Reply to the relation between M\&IE and RPP}

M\&IE and RPP are both valid measures to assess costs of living in different areas and track closely for all institutions analyzed in Card et al. (2020). Figure 1 shows the results of assuming a linear relationship between M\&IE and RPP for all institutions except UHM and UAF. The M\&IE values are from Card et al. (2020) and the RPP values are for goods from the Bureau of Economic Analysis (BEA) website. These metrics have a linear correlation of 0.68 that is significant at the $1 \%$ level. Additionally, recalculating the linear correlation by including UHM and UAF increases the linear cor- relation between M\&IE and RPP to 0.69 and it is still significant at the $1 \%$ level (not shown), reinforcing the notion that M\&IE can be used to assess cost of living. While a nonlinear relationship may have provided a stronger correlation, M\&IE and RPP are significantly related nonetheless. Outliers in this linear correlation could be attributable to the fact that RPP values were last updated in 2018 and the M\&IE values were last updated in 2019. Furthermore, RPP is a value relative to a national mean, while M\&IE values are only a dollar value representing costs.

\section{Reply to other comments in Stuecker at al. (2021)}

Another comment made by Stuecker et al. (2021) includes that exceptional graduate students are routinely offered a higher stipend than what was reported in Card et al. (2020). Several universities noted that occasionally supplemental funding is available for graduate students (e.g., the University of Maryland, College Park). These supplements were
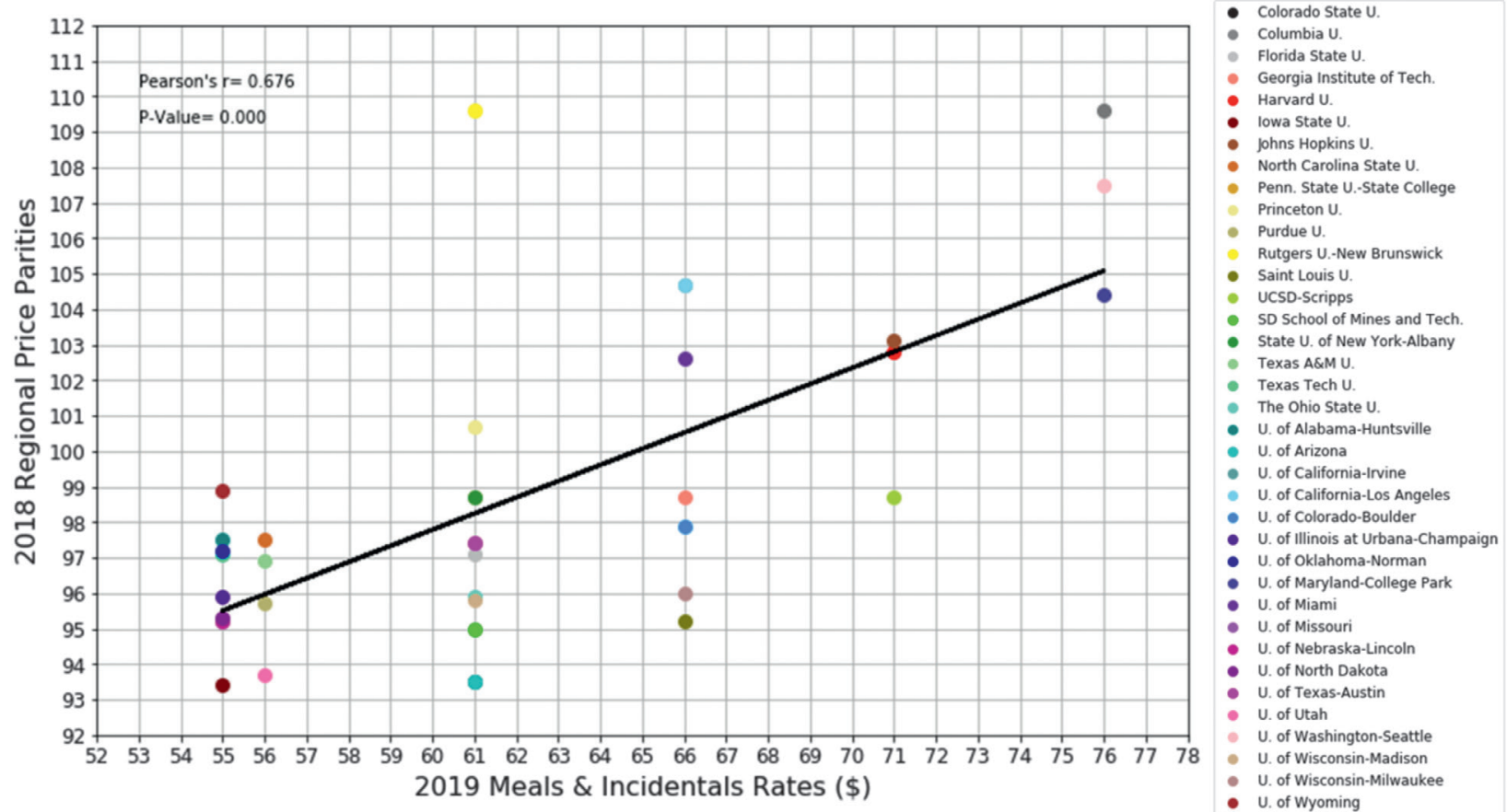

Fig. 1. The relationship between 2018 regional price parities (RPP) and 2019 meals and incidental rates (M\&IE) for all universities analyzed in Card et al. (2020) except for the University of Hawai'i at Mānoa (UHM) and the University of Alaska Fairbanks (UAF). The correlation coefficient and the $p$ value are reported in the figure. 
noted in Card et al. (2020), but not used for analysis since the goal of the study was to assess the typical stipend received. If UHM does routinely offer a higher stipend, that information should have been sent to the authors of Card et al. (2020) during the data collection process. The authors needed to directly contact UHM since the department's website was not clear on the stipend and fee amounts. UHM made no mention of this routinely offered higher stipend and self-reported a stipend of $\$ 31,798$, which was the value used in Card et al. (2020). Program websites should be routinely updated with accurate stipend information as argued in Card et al. (2020) in order to increase transparency. This is especially true for universities located in areas where cost of living poses a significant challenge. Additionally, a potential applicant may not even apply if the financial information is not clear to prospective students.

\section{Concluding remarks}

The comments made by Stuecker et al. (2021) have been addressed by showing how M\&IE and RPP are both appropriate in most circumstances to use for standardization and assessment of cost of living. As Stuecker et al. (2021) state, cost of living in Hawai'i is a significant challenge for the state's population, which could impact prospective and current students, faculty, and staff at UHM. All universities, including UHM, need to continuously monitor cost of living in their area to ensure all persons have sufficient funds for necessities. Additionally, in order to increase transparency and applications, all universities should strive to maintain websites with the most up-todate financial information.

\section{References}

Card, D., H. S. Sussman, and A. Raghavendra, 2020: The financial dilemma of students pursuing an atmospheric science graduate degree in the United States. Bull. Amer. Meteor. Soc., 101, E1524E1536, https://doi.org/10.1175/BAMS-D-19-0122.1.

Stuecker, M. F., C. Karamperidou, A. D. Nugent, G. Torri, S. Coats, and S. Businger, 2021: Comments on "The financial dilemma of students pursuing an atmospheric science graduate degree in the United States." Bull. Amer. Meteor. Soc., 102, 323-324, https://doi.org/10.1175/BAMS-D-20-0265.1. 